\title{
Roles and challenges of traditional Chinese medicine in COVID-19 in Hong Kong
}

Hong Kong Med J 2020;26:268-9

https://doi.org/10.12809/hkmj208564

To the Editor-To date, there are no reported outbreaks of coronavirus disease 2019 (COVID-19) among traditional Chinese medicine (TCM) practitioners and their patients. Traditional Chinese medicine is popular globally, especially in Asian populations such as in Hong Kong. The concept of integrative medicine is appreciated by members of the public. ${ }^{1,2}$ Patients who do not want to be treated by Western medicine often seek TCM herbal remedies instead. Practitioners of TCM are confronted with infection control issues when they treat patients with mild and vague symptoms. Some TCM practitioners wear personal protective equipment, including mask and gown, to protect themselves during consultations. However, several routine TCM manoeuvres are high-risk. In TCM, the tongue is considered to have many relationships and connections in the body, both to the meridians and the internal organs. It is therefore considered essential and important to inspect the tongue for confirming TCM diagnoses. Pulse diagnosis also provides TCM practitioners with information about the health of their patients. In terms of treatment, many TCM procedures such as acupuncture, cupping, and moxibustion are considered high-risk. Various issues are encountered by TCM practitioners $\left(\right.$ Table $\left.^{3-5}\right)$.

There are currently over 10000 TCM practitioners in Hong Kong, compared with 14600 doctors of Western medicine. These TCM practitioners have an important role to contribute in sharing the health burden in the current COVID-19 pandemic, at least in diagnosing and treating mild cases. The role of TCM is now well established and the dispensation, storage, and labelling of Chinese herbal medicines has been regulated since 2003 . In addition, TCM practitioners are regulated and there are plans for a Chinese Medicine Hospital in Tseung Kwan O. ${ }^{6}$ Although there is ongoing research into TCM treatment of COVID-19, the role of the discipline is limited and needs deliberation and recognition..$^{3-5}$

In mainland China, the treatment protocol for diagnosis and treatment for novel coronavirus pneumonia has confirmed the integrative role of TCM in the management of COVID-19.7 Treatment is offered based on stages of disease, namely, prediagnosis, confirmed (mild, moderate, severe, and critical), and rehabilitation. ${ }^{7}$ As with many treatment strategies worldwide, trials are ongoing and there has been no current evidence to support or refute many of the novel treatments, neither in Western nor TCM.

The current policy of the Hong Kong SAR government is that all cases are centralised and managed in the public Hospital Authority system, exclusive of private sector or TCM partners. It is recommended that the Hong Kong SAR government may follow the policy in mainland China to provide TCM as a complementary treatment for in-patients with milder disease as part of the healthcare team responding to COVID-19. In addition, TCM can

TABLE. Issues faced by Chinese medicine practitioners in COVID-19 pandemic in Hong Kong

\begin{tabular}{|c|c|c|}
\hline & Issues & Remarks \\
\hline Clinical & $\begin{array}{l}\text { - High-risk manoeuvres of tongue and pulse } \\
\text { diagnosis } \\
\text { - Common respiratory symptoms of allergic rhinitis } \\
\text { and asthma may be difficult to delineate with URTI } \\
\text { due to COVID-19 } \\
\text { - Documentation and definition of fever } \\
\text { - Training for PPE usage }\end{array}$ & $\begin{array}{l}\text { - Wear surgical mask + face shield } \\
\text { - For suspected cases, wear surgical mask + face } \\
\text { shield + PPE } \\
\text { - Observe hand hygiene during pulse diagnosis } \\
\text { - Routine body temperature measurement before } \\
\text { clinic entry } \\
\text { - Clinic setting restructuring }\end{array}$ \\
\hline Treatment & $\begin{array}{l}\text { - High-risk procedures such as acupuncture, } \\
\text { massage, cupping, and moxibustion }\end{array}$ & $\begin{array}{l}\text { - TCM practitioners to wear surgical mask } \pm \text { PPE } \\
\text { - Request patients to wear surgical masks during } \\
\text { the whole consultation as well as the treatment }\end{array}$ \\
\hline Reporting & $\begin{array}{l}\text { - Confusion as to definitions of exposure, } \\
\text { close contact, infection, carrier, disease state } \\
\text { (asymptomatic vs acute respiratory symptoms vs } \\
\text { coronavirus disease) for reporting }\end{array}$ & $\begin{array}{l}\text { - Train and consolidate referral and contact tracing } \\
\text { mechanisms for TCM practitioners }\end{array}$ \\
\hline Research & - Symptomatic treatment but not evidence-based & $\begin{array}{l}\text { - Review existing research of usefulness of } \mathrm{TCM}^{3-5} \\
\text { - Encourage future research }\end{array}$ \\
\hline
\end{tabular}

Abbreviations: COVID-19 = coronavirus disease 2019; PPE = personal protective equipment; TCM = traditional Chinese medicine; URTI = upper respiratory tract infection 
be offered to patients in the pre-diagnosis and rehabilitation periods for health promotion. There is nothing to lose when patients and citizens see that holistic or integrative medicine is provided by the public system. When further evidence of efficacy is established, TCM can be promoted in the other TCM clinics to serve the public.

The TCM practitioners in Hong Kong have important roles in treating patients with suspected COVID-19 in the community.

\section{Author contributions}

All authors contributed to the concept of the study, acquisition and analysis of the data, drafting of the manuscript, and critical revision of the manuscript for important intellectual content. All authors had full access to the data, contributed to the study, approved the final version for publication, and take responsibility for its accuracy and integrity.

\section{Conflicts of interest}

All authors have no conflicts of interest to disclose.

\section{Funding/support}

This letter received no specific grant from any funding agency in the public, commercial, or not-for-profit sectors.

${ }^{1}$ WL Lin, PhD, BChinMed

1,2 KL Hon *, MB, BS, MD

${ }^{2}$ Karen KY Leung, MB, BS, MRCPCH

${ }^{1} \mathrm{ZX}$ Lin, BSc, PhD

${ }^{1}$ Hong Kong Institute of Integrative Medicine, Faculty of Medicine, The Chinese University of Hong Kong, Hong Kong
2 Department of Paediatrics and Adolescent Medicine, The Hong Kong Children's Hospital, Hong Kong

*Corresponding author: ehon@hotmail.com

\section{References}

1. Hon KL, Leung AK. Integrative, integrated medicine but no integration: Tarnishing steroid and Chinese medicine is vanity. Hong Kong J Paediatr 2018;23:192-4.

2. Hon KL, Leung AK, Leung TN, Lee VW. Complementary, alternative and integrative medicine for childhood atopic dermatitis. Recent Pat Inflamm Allergy Drug Discov 2017;11:114-24.

3. Ren JL, Zhang AH, Wang XJ. Traditional Chinese medicine for COVID-19 treatment. Pharmacol Res 2020;155:104743.

4. Chan KW, Wong VT, Tang SC. COVID-19: An update on the epidemiological, clinical, preventive and therapeutic evidence and guidelines of integrative Chinese-Western medicine for the management of 2019 novel coronavirus disease. Am J Chin Med 2020;48:737-62.

5. Gray PE, Belessis Y. The use of Traditional Chinese Medicines to treat SARS-CoV-2 may cause more harm than good. Pharmacol Res 2020;156:104776.

6. Hong Kong SAR government. Prequalification for operation of Chinese Medicine Hospital in Tseung Kwan O (with video). 13 September 2019. Available from: https://www. info.gov.hk/gia/general/201909/13/P2019091200691.htm. Accessed 4 May 2020.

7. National Health Commission \& State Administration of Traditional Chinese Medicine. Diagnosis and treatment protocol for novel coronavirus pneumonia; 2020. Available from: https://www.chinadaily.com.cn/pdf/2020/1.Clinical. Protocols.for.the.Diagnosis.and.Treatment.of.COVID-19. V7.pdf. Accessed 4 May 2020. 